\title{
QUEEN'S
UNIVERSITY
BELFAST
}

\section{DNA vaccination for cervical cancer: Strategic optimisation of RALA mediated gene delivery from a biodegradable microneedle system.}

Cole, G., Ali, A., McCrudden, C., McBride, J., McCaffrey, J., Robson, T., Kett, V., Dunne, N., Donnelly, R., \& McCarthy, H. (2018). DNA vaccination for cervical cancer: Strategic optimisation of RALA mediated gene delivery from a biodegradable microneedle system. European Journal of Pharmaceutics and Biopharmaceutics, 127, 288-297. https://doi.org/10.1016/j.ejpb.2018.02.029

Published in:

European Journal of Pharmaceutics and Biopharmaceutics

Document Version:

Publisher's PDF, also known as Version of record

Queen's University Belfast - Research Portal:

Link to publication record in Queen's University Belfast Research Portal

Publisher rights

(c) 2018 Elsevier B.V. All rights reserved. This work is made available online in accordance with the publisher's policies. Please refer to any applicable terms of use of the publisher.

\section{General rights}

Copyright for the publications made accessible via the Queen's University Belfast Research Portal is retained by the author(s) and / or other copyright owners and it is a condition of accessing these publications that users recognise and abide by the legal requirements associated with these rights.

Take down policy

The Research Portal is Queen's institutional repository that provides access to Queen's research output. Every effort has been made to ensure that content in the Research Portal does not infringe any person's rights, or applicable UK laws. If you discover content in the Research Portal that you believe breaches copyright or violates any law, please contact openaccess@qub.ac.uk. 


\section{Accepted Manuscript}

Research paper

Jurepean

lourial of

Pharmaceuties and

i) iophapmacentios

DNA vaccination for cervical cancer: Strategic optimisation of RALA mediated gene delivery from a biodegradable microneedle system

Grace Cole, Ahlam A. Ali, Cian M. McCrudden, John W. McBride, Joanne McCaffrey, Tracy Robson, Vicky L. Kett, Nicholas J. Dunne, Ryan F. Donnelly, Helen O. McCarthy

PII: S0939-6411(17)31334-6

DOI: https://doi.org/10.1016/j.ejpb.2018.02.029

Reference: EJPB 12709

To appear in:

European Journal of Pharmaceutics and Biopharmaceutics

Received Date: $\quad 19$ November 2017

Revised Date: $\quad 20$ February 2018

Accepted Date: $\quad 20$ February 2018

Please cite this article as: G. Cole, A.A. Ali, C.M. McCrudden, J.W. McBride, J. McCaffrey, T. Robson, V.L. Kett, N.J. Dunne, R.F. Donnelly, H.O. McCarthy, DNA vaccination for cervical cancer: Strategic optimisation of RALA mediated gene delivery from a biodegradable microneedle system, European Journal of Pharmaceutics and Biopharmaceutics (2018), doi: https://doi.org/10.1016/j.ejpb.2018.02.029

This is a PDF file of an unedited manuscript that has been accepted for publication. As a service to our customers we are providing this early version of the manuscript. The manuscript will undergo copyediting, typesetting, and review of the resulting proof before it is published in its final form. Please note that during the production process errors may be discovered which could affect the content, and all legal disclaimers that apply to the journal pertain. 


\section{DNA vaccination for cervical cancer: Strategic optimisation of}

\section{RALA mediated gene delivery from a biodegradable microneedle}

\section{system}

Grace Cole ${ }^{1}$, Ahlam A. Ali ${ }^{1}$, Cian M. McCrudden ${ }^{1}$, John W. McBride ${ }^{1}$, Joanne McCaffrey ${ }^{2}$, ,

Tracy Robson ${ }^{1,3}$, Vicky L. Kett ${ }^{1}$, Nicholas J. Dunne ${ }^{1,4}$, Ryan F. Donnelly ${ }^{1}$, Helen O. McCarthy $^{1 *}$

*Corresponding Author

${ }^{1}$ School of Pharmacy, Queen's University Belfast, Belfast BT9 7BL, Northern Ireland, UK

${ }^{2}$ Department of Pharmacology and Therapeutics, University College Cork, Cork T12 YN60, Ireland

${ }^{3}$ Molecular \& Cellular Therapeutics, Royal College of Surgeons in Ireland, Dublin 2, Ireland

${ }^{4}$ School of Mechanical and Manufacturing Engineering, Dublin City University, Dublin 9, Ireland

Email: h.mccarthy@qub.ac.uk

Tel.: +44 02890972149

Fax: +44 02890247794 


\section{Abstract}

Dissolvable microneedles can be employed to deliver DNA to antigen presenting cells within the skin. However, this technology faces two main challenges: the poor transfection efficacy of pDNA following release from the microneedle matrix, and the limited loading capacity of the micron-scale devices. Two-tier delivery systems combining microneedle platforms and DNA delivery vectors have increased efficacy but the challenge of increasing the loading capacity remains. This study utilised lyophilisation to increase the loading of RALA/pDNA nanoparticles within dissolvable PVA microneedles. As a result, delivery was significantly enhanced in vivo into an appropriate range for DNA vaccination ( $\sim 50 \mu \mathrm{g}$ per array). Furthermore, modifying the manufacturing process was not detrimental to the microneedle mechanical properties or cargo functionality. It was demonstrated that arrays retained mechanical and functional stability over short term storage, and were able to elicit gene expression in vitro and in vivo. Finally, treatment with this novel formulation significantly retarded the growth of established tumours, and proved superior to standard intramuscular injection in a preclinical model of cervical cancer.

Key Words: DNA Vaccine; Microneedle; RALA; Lyophilisation; Nanoparticle; Cervical Cancer 


\section{Introduction}

The advantages of DNA vaccines include: elicitation of potent therapeutic and prophylactic immune responses $;{ }^{[1]}$ high stability leading to lower production and storage costs; ${ }^{[2]}$ and flexibility of design through control of the nucleotide sequence allowing multiple antigens and/or adjuvants within one plasmid. ${ }^{[3,4]}$ Despite DNA vaccines demonstrating good safety and tolerability, the induction of meaningful immune responses through simple injection has proven difficult to achieve in human trials, because of the extra- and intracellular biological barriers to gene delivery. ${ }^{[5,6]}$ Microneedles (MNs), consist of multiple sharp projections less than $1000 \mu \mathrm{m}$ in length secured to a baseplate and can pierce the stratum corneum (SC), creating transient pores for delivery of genetic cargo to the viable epidermis and dermis, overcoming such extracellular barriers. ${ }^{[7]}$ These are ideal sites for vaccine delivery due to the high population of resident antigen presenting cells (APCs), (such as epidermal Langerhan Cells [LCs] and dermal dendritic cells [DCs]), which are essential to the induction of CD8+ T cells, the effectors of the adaptive immune system that can destroy antigen expressing target cells. ${ }^{[8,9]}$ The dermal layers of the skin also harbour an extensive lymph network, providing drainage for activated DCs and enabling rapid T cell priming. ${ }^{[10]}$ Furthermore, delivery via MN increases the chances of transfecting both APC and non-APCs compared to a single needle injection. ${ }^{[11]}$ Other advantages of $\mathrm{MN}$ include self-application, ${ }^{[12]}$ minimal storage requirements, ${ }^{[13]}$ and pain-free delivery thereby increasing patient acceptability. ${ }^{[14]}$

To date, a number of MN designs including solid,${ }^{[15]}$ coated, ${ }^{[16]}$ hollow, ${ }^{[17]}$ and most recently, dissolvable ${ }^{[18]}$ have been utilised to deliver DNA in preclinical studies. Of these, coated and dissolvable arrays provide the advantage of combining the vaccine cargo into the delivery device. A limitation of coated MN arrays is the relatively small dose that researchers can achieve without compromising needle conformation and hence penetration. ${ }^{[19,20]}$ As such dissolvable arrays may be more suitable for DNA vaccination as the cargo may be 
incorporated throughout the entire matrix of the $\mathrm{MN}$ thereby increasing potential loading capacity. ${ }^{[21,22]}$ Dissolvable MN arrays further remove the inherent danger of needle buckling or breakage within the skin, minimise the risk of abuse or reuse, and provide a means to visually confirm dosage delivery. ${ }^{[17]}$

Previously, we reported on the design of a dissolvable Poly(Vinyl Pyrrolidine) (PVP) MN system incorporating pDNA cargo complexed to the cationic cell-penetrating peptide, RALA, to aid intra-cellular uptake. ${ }^{[13,23]}$ This device was capable of inducing robust humoural and cellular immune responses against the Human Papillomavirus (HPV) cervical cancer Tumour Associated Antigens (TAAs), E6 and E7. ${ }^{[24]}$ Furthermore, immunisation of mice utilising this dissolvable MN system decreased tumour uptake in both prophylactic and therapeutic tumour models. ${ }^{[24]}$ By thoroughly screening a range of dissolvable polymers for the $\mathrm{MN}$ fabrication process, this device has been further optimised to increase cargo transfection efficacies and payload. ${ }^{[22]}$ Despite these improvements, increasing the quantity of pDNA vaccine delivered from dissolvable MNs remains a considerable challenge. Therefore, the current study was designed to determine whether lyophilisation could be used to facilitate increased loading of the RALA/pDNA nanoparticle (NP) cargo within the dissolvable MN matrix, without compromising needle integrity or functionality. Firstly, a suitable lyophilisation process for NPs was identified. A novel MN formulation technique incorporating lyophilised NPs (LNPs) into a dissolvable 9-10 kDa PVA matrix was developed with in vitro and in vivo studies to demonstrate functionality. Finally, the superiority of the device compared to conventional i.m. injection was established in a therapeutic DNA vaccination study in a murine cervical cancer model. 


\section{Materials and Methods}

\subsection{Formation of RALA/pDNA Nanoparticles (NP)}

The RALA peptide (WEARLARALARALARHLARALARALRACEA) was synthesised by Biomatik Corporation (USA), and reconstituted in DNase/RNase free water (Life Technologies, UK) for experimentation. Plasmids encoding green fluorescent protein (GFP), pEGFP-N1 (Clontech, USA), Firefly Luciferase, pLUX, and HPV-16 E6 and E7, pE6-E7 (Addgene, USA), were transformed into competent Escherichia coli DH5 $\alpha$ cells (Life Technologies, UK) and amplified prior to use as per the manufacturer's instructions. Plasmids were isolated and purified using PureLink HiPure Plasmid Filter Maxiprep Kits (Life Technologies, UK), and reconstituted in DNase/RNase fee water. Plasmid purity and concentration was determined using a NanoDrop 2000c (Thermo Scientific, UK) according to UV absorbance at $260 \mathrm{~nm}$ and $280 \mathrm{~nm}$.

RALA/pDNA complexes were prepared by mixing pDNA with increasing amounts of RALA peptide at varying N:P ratios from $0-12$ as previously described, ${ }^{[23]}$ and incubating for $30 \mathrm{~min}$ at room temperature (RT) to facilitate electrostatic interaction.

\subsection{Lyophilisation Protocol for NPs}

Unless otherwise stated, NP solutions were diluted 3:1 with $20 \%$ w/v trehalose (Sigma Aldrich, UK), to give a final concentration of $5 \% \mathrm{w} / \mathrm{v}$ trehalose. Solutions were transferred into a VirTis Wizard 2.0 (SP Scientific, USA) and subjected to freezing for $1 \mathrm{~h}$ at $-40^{\circ} \mathrm{C}$, before primary drying at $-35^{\circ} \mathrm{C}$ for $3 \mathrm{~h}(120 \mathrm{mTorr}),-30^{\circ} \mathrm{C}$ for $4 \mathrm{~h}(190 \mathrm{mTorr})$ and $-25^{\circ} \mathrm{C}$ for $4 \mathrm{~h}$ (190 mTorr). Finally, samples underwent secondary drying at $20^{\circ} \mathrm{C}$ for $18 \mathrm{~h}(190 \mathrm{mTorr}$ for $8 \mathrm{~h}$ and $50 \mathrm{mTorr}$ for $10 \mathrm{~h}$ ). Lyophilised samples were stored at RT until required for experimentation. 


\subsection{Characterisation of Fresh NPs (F-NPs) and lyophilised NPs (L-NPs)}

$50 \mu \mathrm{L}$ samples of F-NPs or L-NPs (N:P 6) containing $1 \mu \mathrm{g}$ of pDNA were loaded into polystyrene microcuvettes (Malvern Instrument Ltd, UK) and complex mean hydrodynamic size was determined by Dynamic Light Scattering using the Malvern Zetasizer NanoZS (Malvern Instrument Ltd, UK). Samples were diluted with $950 \mu \mathrm{L}$ of DNase/RNase free water and transferred into a zeta-cuvette (Malvern Instrument Ltd, UK) for surface charge (zeta potential) determination using the Malvern Zetasizer NanoZS by Laser Doppler Velocimetry.

F-NPs and L-NPs (N:P ratios 0-12) were prepared with $3 \mu \mathrm{g}$ of pEGFP-N1 in a volume of 75 $\mu \mathrm{L}$. For gel retardation assays $10 \mu \mathrm{L}$ of sample was supplemented with Nucleic Acid Loading Buffer (Bio-Rad, USA), loaded on to a 1\% Agarose gel, and electrophoresed at $100 \mathrm{~V}$ for $1 \mathrm{~h}$ in 1X TAE buffer before visualising under UV light using a Multispectrum Bioimaging System (UVP, UK). To allow examination of pDNA tertiary structure, $10 \mu \mathrm{L}$ samples were supplemented 1:1 with $1.0 \mathrm{mg} / \mathrm{mL}$ Proteinase K (Sigma, UK) and incubated for $120 \mathrm{~min}$ at $37^{\circ} \mathrm{C}$ to allow degradation of the RALA peptide. Samples were then electrophoresed as above.

To determine the NP encapsulation efficacy, $50 \mu \mathrm{L}$ samples were diluted 1:2 with TAE buffer and placed in a black 96 well plate. Samples were incubated with $50 \mu \mathrm{L}$ of diluted Quant-iT PicoGreen reagent (Life Technologies, UK) for $30 \mathrm{~min}$ at RT, excited by fluorescence at $480 \mathrm{~nm}$ and the fluorescent emission at $520 \mathrm{~nm}$ was measured using a Synergy 2 Multi-Mode Microplate Reader (BioTek Instruments Inc, UK). Percentage accessible pDNA was calculated relative to the fluorescence of pDNA only controls at $100 \%$.

\subsection{In vitro assessment of NPs}


In vitro assessment of F-NPs and L-NPs was performed in NCTC-929 cells, a murine fibroblast cell line which is recommended by ATCC for transfection and toxicity studies (https://www.lgcstandards-atcc.org/products/all/CCL-1). For cytotoxicity assays NCTC-929 fibroblast cells (ATCC) were seeded into 96 well plates (10,000 cells/well), left to adhere overnight, and conditioned with Opti-MEM (Life Technologies, UK) for $2 \mathrm{~h}$. Cells were supplemented with $50 \mu \mathrm{L} /$ well of F-NPs or L-NPs (N:P 0-10) containing $1 \mu \mathrm{g}$ of pDNA. Cells were incubated with complexes for $6 \mathrm{~h}$ at $37^{\circ} \mathrm{C}$ before being replaced in complete media. $24 \mathrm{~h}$ following transfection cells were supplemented with 10\% CellTiter 96 Aqueous One Solution Reagent (MTS) (Promega, UK), and percentage toxicity was determined as previously described. ${ }^{[22]}$

For transfection studies NCTC-929 cells were seeded into 24 well plates (100,000 cells/well) and treated with NPs as above, with a total of $5 \mu \mathrm{g}$ of pDNA/well. Cells were treated with FNPs, L-NPs or L-NPs which had been resuspended and dried in PVA. F-NPs or L-NPs (N:P 6) were prepared with $5 \mu \mathrm{g}$ of pDNA in a volume of $40 \mu \mathrm{L}$. PVA gels were prepared by resuspending L-NPs (N:P 6) containing $20 \mu \mathrm{g}$ pDNA in $250 \mathrm{mg}$ of aqueous $20 \% \mathrm{w} / \mathrm{w} 9-10$ kDa PVA stock solution. Once a homogenous solution had been formed, samples were transferred into non-indented silicon master-moulds using a spatula, and left to dry overnight. Gels containing RALA/pEGFP-N1 were subsequently stored at RT $\left(21^{\circ} \mathrm{C}\right)$ for up to 28 days prior to use, while gels containing RALA/pE6-E7 were stored at $4{ }^{\circ} \mathrm{C}, 21^{\circ} \mathrm{C}$ or $37^{\circ} \mathrm{C}$ for 28 days. Gels were peeled carefully from the master-mould, and dissolved in $1000 \mu \mathrm{L}$ of OptiMEM solution for $2 \mathrm{~h}$ at $37^{\circ} \mathrm{C}, 250 \mu \mathrm{L}$ of the solution was then used for transfection.

GFP expression was visualised $48 \mathrm{~h}$ post transfection using an EVOS FL Cell Imaging System (Thermofisher Scientific, UK). Cells were harvested in 2\% Formaldehyde, and GFP expression was quantified via flow cytometry using the FACS caliber system (BD 
Biosciences, UK). Data was analysed using CellQuestPro software (BD Biosciences, UK). Fluorescent intensity is reported at $4 \%$ gating to untreated cells.

For determination of expression of the HPV-16 E6 and E7 proteins, cells were harvested in radio immune precipitation assay (RIPA) buffer $48 \mathrm{~h}$ following transfection. Samples $(20 \mu \mathrm{g})$ were electrophoresed through a 4-12\% sodium dodecyl (SDS)-polyacrylamide gel (Life Technologies, UK), transferred onto a nitrocellulose membrane (Hybond-C, Amersham; UK) and probed with HPV-16 E6 and HVP-16 E7 antibodies (Abcam; UK). GAPDH was used as a loading control (Sigma; UK). Levels of protein expression were assessed using an Immobilon western detection kit (Millipore; UK). X-ray films were scanned using benchtop UV transilluminators (UVP Products Ltd) and density was calculated using Image $\mathbf{J}$ (http://rsbweb.nih.gov/ij/) incorporating correction of loading controls.

\subsection{Microneedle (MN) Fabrication}

For fabrication of MNs, L-NPs (N:P 6) were prepared using $100 \mu \mathrm{g}$ of pDNA. $30 \mathrm{mg}$ of $20 \%$ w/w 9-10 kDa PVA solution was used to reconstitute the lyophilisate and once a homogenous mixture had been formed, the PVA-NP solution was transferred into a silicon mould containing 19x19 inverted conical projections with dimensions of $300 \mu \mathrm{m}$ diameter and 600 $\mu \mathrm{m}$ length, spaced $50 \mu \mathrm{m}$ apart, which has been described elsewhere. ${ }^{[25]}$ PVA-NP was centrifuged for $5 \mathrm{~min}$ at $4,000 \mathrm{rpm}$ to fill the projections. Following centrifugation $500 \mathrm{mg}$ of inert 20\% w/w 9-10 kDa PVA solution was added above the filled projections and recentrifuged to form an empty baseplate. Needles were left to dry for $48 \mathrm{~h}$ at RT before removal from the mould (Figure 2C).

\subsection{Visual assessment and mechanical testing of MN needle arrays}

The sidewalls of MN arrays were removed with scissors. Arrays were subsequently adhered to a flat metal block using double-sided sticky tape, faced perpendicularly to the lens of a 
Leica EZ4D digital microscope (Leica, Germany) and imaged at x35. For compression studies, MNs were stored at RT for up to 28 days prior to analysis. Needles were pressed against a flat aluminium block using the movable probe of the TA-XT2 Texture Analyser (Stable Microsystems, UK), with a force of $45 \mathrm{~N}(0.125 \mathrm{~N} /$ needle), for 30 s. Following compression, the needles were re-imaged using the Leica EZ4D digital microscope. The percentage needle height reduction was subsequently determined as previously described. ${ }^{[22]}$

\subsection{Assessment of MN penetration into neonatal porcine skin via Optical Coherence Tomography (OCT)}

Full thickness neonatal porcine skin was harvested from stillborn piglets and stored at $-20^{\circ} \mathrm{C}$ between experiments. Prior to analysis, skin was thawed in PBS at $37^{\circ} \mathrm{C}$ for $30 \mathrm{~min}$ and hair was carefully removed using a disposable razor. Skin was placed onto a sheet of dental wax for support, with the SC side facing up, and cleaned with a $70 \%$ Ethanol wipe prior to MN insertion. A piece of sticky tape was placed over the flat side of the baseplate of MNs loaded with NP (NP-MN) or pDNA (DNA-MN), and MNs were subsequently placed onto the SC surface, inserted into the skin using manual thumb pressure, and held in place for $30 \mathrm{~s}$. 2D images of needle penetration were obtained using an EX1301 OCT microscope (Michelson Diagnostics Ltd, UK) and Image J software (National Institutes of Health, USA) was used to analyse images of penetration as previously described. ${ }^{[22]}$

\subsection{Quantification of pDNA encapsulation within the microneedle array}

The quantity of pDNA residing in the MN was determined using the PicoGreen assay as described previously. ${ }^{[13,22]}$ Briefly, the sidewalls, and the arrays (baseplate and needles) were dissolved in $10 \mathrm{mM}$ TRIS buffer $(\mathrm{pH} 8)$, incubated with $1.0 \mathrm{mg} / \mathrm{mL}$ Proteinase $\mathrm{K}$ for $2 \mathrm{~h}$ at $37^{\circ} \mathrm{C}$, and $50 \mu \mathrm{L}$ samples were supplemented with Quanti-iT PicoGreen reagent. The quantity of released pDNA was determined using a standard curve. 


\subsection{Application of NP-laden dissolvable microneedles in vivo}

All animal experiments complied with the UK Scientific Act and were carried out under Project License 2794. For all experiments MNs were applied to the dorsal side of the ears of female C57 BL/6 mice (6-8 weeks old). Application was as previously described, ${ }^{[22]}$ where unless stated otherwise MNs were held into the skin for 5 min prior to being adhered in place for a further $24 \mathrm{~h}$ with $3 \mathrm{M}$ Surgical tape (Micropore Ltd, UK). After this time arrays were removed by wetting the tape and gently peeling.

\subsection{Quantification of NP delivery from dissolvable microneedles in vivo}

To provide an estimate of delivery from MNs, NP-MNs were applied to the ears of mice for either 5 min with pressure or for 5 min with manual pressure followed by taping arrays in place for $24 \mathrm{~h}$. Following removal, the quantity of pDNA remaining in the MN was determined using the PicoGreen assay. pDNA delivery was estimated by subtracting the quantity of pDNA remaining in $\mathrm{MN}$ following application from the quantity of pDNA in unapplied MNs.

\subsection{Quantification of Luciferase expression using quantitative real-time polymerase chain reaction (qRT-PCR)}

Mice were treated with MNs manufactured with $32 \mu \mathrm{g}$ of non-lyophilised pLUX (N:P 6), prepared as previously described, ${ }^{[22]}$ or with MNs manufactured with $100 \mu \mathrm{g}$ of L-pLUX (N:P 6). $48 \mathrm{~h}$ following application, the whole ear was harvested and placed TriZol@ (Thermofisher Scientific, UK) reagent for mRNA extraction. Tissues were homogenised by oscillating in a TissueLyser LT (Qiagen, UK) at $50 \mathrm{osc} / \mathrm{sec}$ for $10 \mathrm{~min}$ and subsequently following the manufacturer's instructions. RNA purity and concentration were determined according to UV absorbance at $260 \mathrm{~nm}$ and $280 \mathrm{~nm}$. mRNA was treated to remove contaminating DNA using a DNase I, RNase-free kit (Thermofischer Scientfic, UK) as per 
the manufacturer's instructions. To allow conversion of mRNA to cDNA, $1 \mu \mathrm{g}$ of mRNA was added to $10 \mu \mathrm{L}$ of Reverse Transcription mix ( $4 \mu \mathrm{L} 5 \mathrm{X}$ First Strand Buffer, $1 \mu \mathrm{L} 10 \mathrm{mM}$ dNTP mix, $1 \mu \mathrm{L}$ Dilute Random Primer, $2 \mu \mathrm{L}$ 0.1 M DTT, $1 \mu \mathrm{L}$ RNase OUT 40U/mL, $1 \mu \mathrm{L}$ M-MLV Reverse Transcriptase, [ Invitrogen, UK]). Samples were heated to $25^{\circ} \mathrm{C}$ for $5 \mathrm{~min}$, $37^{\circ} \mathrm{C}$ for $90 \mathrm{~min}$, and $70^{\circ} \mathrm{C}$ for $10 \mathrm{~min}$, before being cooled to $4^{\circ} \mathrm{C}$. Following reverse transcription, $1 \mu \mathrm{L}$ of cDNA sample was transferred to a qRT-PCR 96 well plate (Roche, UK). $9 \mu \mathrm{L}$ of Mastermix ( $5 \mu \mathrm{L}$ SYBR Green [Roche, UK], $3 \mu \mathrm{L}$ DNase/RNase free water, 1 $\mu \mathrm{L}$ primer) was added to each sample. Primers were designed using the NCBI Primer Blast program and fabricated by Integrated DNA Technologies (UK), the Luciferase forward and reverse primer sequences were 5'-TCGTGACTTCCCATTTGCCA-3' and 5'GGGATGATCTGGTTGCCGAA-3' respectively, $\beta$-actin forward and reverse primer sequences were 5'-AGA AAA TCT GGC ACC ACA CC-3' and 5'-TAG CAC AGC CTG GAT AGC AA-3' respectively. Plates were placed in to a Lightcycler 480 II (Roche, UK) and incubated at $95^{\circ} \mathrm{C}$ for $5 \mathrm{~min}$, before amplification for 45 cycles at $95^{\circ} \mathrm{C}$ for $10 \mathrm{~s}, 60^{\circ} \mathrm{C}$ for $10 \mathrm{~s}$ and $72^{\circ} \mathrm{C}$ for $10 \mathrm{~s}$. Ct values were generated by the machine's software, and were used to quantify the expression of Luciferase relative to the $\beta$-actin housekeeper gene, Luciferase expression is reported relative to untreated control.

\subsection{Quantification of luciferase expression in vivo via bioluminescence imaging}

MNs containing lyophilised pDNA (DNA-MN) or NPs (NP-MN) were applied to mice. $24 \mathrm{~h}$ following MN removal, mice were injected i.p. with $200 \mu \mathrm{L}$ of D-Luciferin $(15 \mathrm{mg} / \mathrm{mL})$ and luminescence was detected 10 min later via whole body imaging using the In-Vivo Xtreme Imaging System (Bruker, UK). Emission images were captured for $5 \mathrm{~min}$ and the luminescence of individual ears was determined using LivingImage 3.2 software (Leica, UK). Mice were then sacrificed via schedule 1 killing, and the organs were harvested, transferred 
to a 6 well plate, and bathed in $15 \mathrm{mg} / \mathrm{mL}$ D-Luciferin for a further $10 \mathrm{~min}$ prior to imaging as above.

\subsection{Immunisation of mice}

Mice were divided into treatment groups and immunized with $100 \mu \mathrm{g}$ of pE6-E7. The treatment groups were as follows: untreated control, naked pDNA via i.m. injection (DNAIM), naked pDNA via MN (DNA-MN), NP via i.m. injection (NP-IM) and NP via MN (NP$\mathrm{MN})$. For MN treatment, one MN was applied to each ear. Vaccination was followed by a $2^{\text {nd }}$ and $3^{\text {rd }}$ booster immunisation every 2 weeks.

\subsection{ELISA for detecting anti-E6/E7 antibodies}

An indirect ELISA was carried out one week after the $2^{\text {nd }}$ and $3^{\text {rd }}$ boosts to determine E6/E7 specific IgG antibodies in mice sera. A Nunc MaxiSorp 96 well plate (ThermoFisher Scientific, UK) was coated with $100 \mu \mathrm{l}$ of purified HPV-16 E7/E6 peptides (ProImmune, UK) at $0.5 \mathrm{mg} / \mathrm{ml}$ and incubated at $4^{\circ} \mathrm{C}$ overnight. After washing with PBS containing $0.05 \%$ Tween 20, the wells were then blocked with PBS containing $20 \%$ fetal bovine serum and incubated at $4^{\circ} \mathrm{C}$ for $16 \mathrm{~h}$. Serum samples diluted in PBS $(1: 100)$ were added to the ELISA wells, and incubated at $37^{\circ} \mathrm{C}$ for $2 \mathrm{~h}$. After washing with PBS/Tween 20 , the plate was incubated with a 1:2000 dilution of a goat anti-mouse IgG HRP-conjugated antibody (Sigma, UK) at RT for $1 \mathrm{~h}$. After a final wash, an enzyme substrate (OPD, Sigma) was added for colour development. Immuno-reactivity was detected with an ELISA plate reader at $450 \mathrm{~nm}$. Quantification of IgG was performed using an Easy Titer IgG assay kit (Thermo scientific, UK) with a standard curve.

\subsection{Cytotoxicity and Interferon(IFN)- $\gamma$ assay}

One week following the $3^{\text {rd }}$ immunization, the spleen from each mouse was removed, homogenized and re-suspended in Red Blood Cell (RBC) lysis buffer (Sigma, UK) to remove 
RBCs. T cells (effecter cells) were co-cultured at a ratio of 10:1 with irradiated TC-1 cells $\left(10^{4}\right.$ per well) (target cells) in RPMI-1640 medium with 20 units of interleukin-2 (Peprotech, UK) in 24-well plates at $37^{\circ} \mathrm{C}$. Dead T cells were removed by centrifugation with Percoll solution (Amersham Biosciences) for up to 6 days. Following 4 days of stimulation, the supernatant of each sample was taken and debris was removed by centrifugation. IFN- $\gamma$ was detected using an IFN- $\gamma$ ELISA kit (Peprotech, UK) as per the manufacturer's instructions. Following 6 days stimulation viable T cells were seeded with non-irradiated TC-1 cells at a ratio of $10: 1$ in $1 \% \mathrm{BSA}$ medium, at $37^{\circ} \mathrm{C}$ for $5 \mathrm{~h}$ in 96 -well plates. After $5 \mathrm{~h}$, the supernatant of each sample was collected and TC-1 cytotoxicity was measured using a LDH cytotoxicity detection kit as per the manufacturer's instructions (Roche, UK).

\subsection{Tumour therapeutic assay}

Female C57BL/6 mice were challenged i.d. on the rear dorsum with $1 \mathrm{X} 10^{5}$ TC- 1 cells. When tumours reached $50 \mathrm{~mm}^{3}$, mice were immunized three times as stated in section 2.13 , but at weekly intervals. Mice were monitored for evidence of tumour growth by palpation and measurement with callipers three times a week. All mice were culled one week following the $3^{\text {rd }}$ immunization and tumour weights were analysed.

\subsection{Statistical Analysis}

Unless otherwise stated, all experiments had three independent repeats. Results are expressed as the mean \pm standard deviation (SD). Statistical differences between groups were determined using a two-tailed, unpaired $\mathrm{t}$ test, or a One-Way ANOVA, with a $\mathrm{P}$ value $\leq 0.05$ considered significant. For all analyses, data sets were assumed to be normal and possess homogeneity of variance. 


\section{Results}

\subsection{Characterisation of F-NP and L-NPs}

(A)

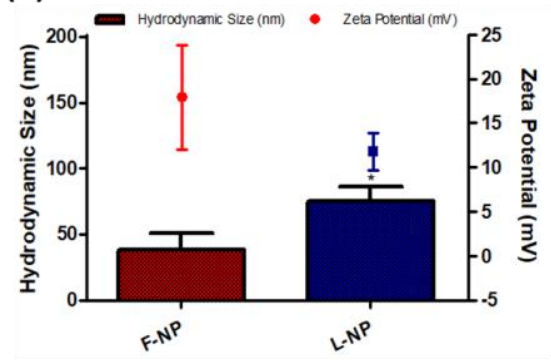

(D)

i)

ii)
(B)

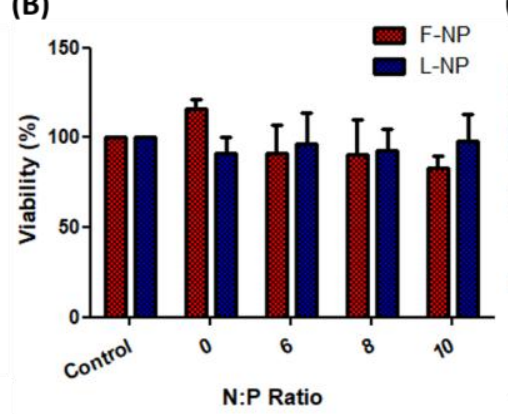

(E)
(C)

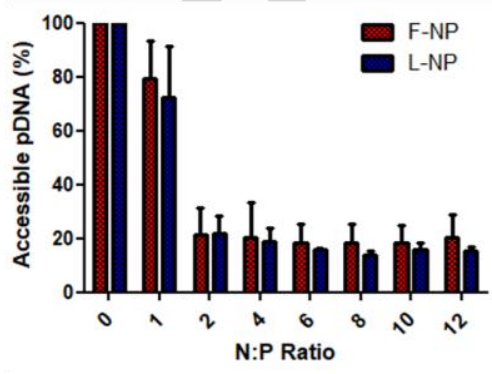

ii)

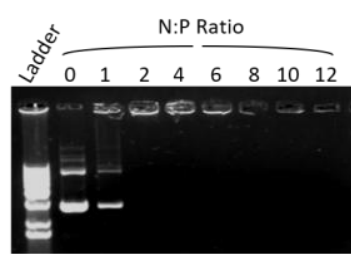

i)

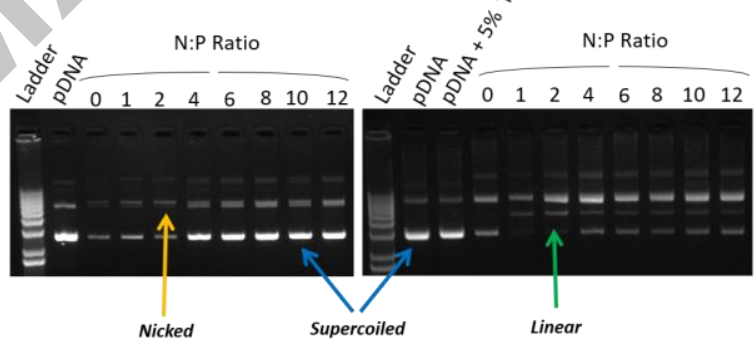

Figure 1. Characterisation of Fresh Nanoparticles (F-NPs) and Lyophilised NPs (L-NPs). (A) FNP and L-NP size and zeta potential (N:P 6). Asterisk denotes a significant difference (Student's ttest, $* \mathrm{p}<0.05)$. (B) Cytotoxicity of NPs over a range of N:P ratios $(0-10)$ in the NCTC-929 cell line by MTS; (C) Encapsulation Efficiency of NPs over a range of N:P ratios (0-12); (D) Gel retardation assay of (i) F-NPs and (ii) L-NPs at various N:P ratios (0-12). i) Lane 1: DNA Ladder; Lanes 2-9: FNPs prepared at N:P ratios 1-12, ii) Lane 1: DNA Ladder; Lane 2: pDNA only; Lane 3: pDNA + 5\% trehalose (T); Lanes 4-11: L-NPs prepared at N:P ratios 1-12. (E) DNA integrity study of (i) F-NPs and (ii) L-NPs at various N:P ratios (0-12). Lane map as per (D). Decomplexation with of NPs with proteinase K. Graphs represent mean $+\mathrm{SD}$ ( $\mathrm{N}=3$ for all studies).

F-NPs had a mean hydrodynamic size of $37.96 \mathrm{~nm}$ and a zeta potential of $17.92 \mathrm{mV}$. Following lyophilisation, NP mean hydrodynamic size increased significantly to $74.93 \mathrm{~nm}$ (p 
$<0.05)$ (Figure 1-A), however the zeta potential of L-NPs showed no significant difference to F-NPs $(11.77 \mathrm{mV}, \mathrm{p}>0.05)$. The affect of $\mathrm{N}: \mathrm{P}$ ratio and lyophilisation on cell viability was next assessed in the NCTC-929 cell line by MTS assay $24 \mathrm{~h}$ following transfection (Figure 1B). Transfection with F-NPs or L-NPs did not result in a significant decrease in cell viability compared to control, and no drop in viability below $80 \%$ of untreated controls was observed across the range of transfection conditions (Figure 1-B). The encapsulation efficiency of FNPs and L-NPs was determined via the PicoGreen assay, which has been utilised previously to determine changes in NP structure following lyophilisation. ${ }^{[26]}$ Consistent with previously reported data, ${ }^{[23]}$ as the $\mathrm{N}: \mathrm{P}$ ratio of $\mathrm{F}-\mathrm{NPs}$ increased, the percentage of accessible pDNA within solutions decreased, from $100 \%$ at $\mathrm{N}: \mathrm{P} 0$, to $79.2 \%$ at $\mathrm{N}: \mathrm{P} 1$, and at $\mathrm{N}: \mathrm{P}$ ratios $\geq 2$ approximately $20 \%$ of pDNA was accessible to PicoGreen, due to pDNA being complexed to RALA. The percentage of pDNA accessible to PicoGreen within L-NPs was similar to that of F-NPs with $72.4 \%$ of pDNA binding PicoGreen at N:P 1, and at higher N:P ratios approximately $20 \%$ of pDNA from L-NPs was able to bind PicoGreen (Figure 1-C). The gel retardation assay was next used to determine the ability of the RALA peptide to neutralise the charge of negatively charged pDNA. RALA neutralised the charge of pEGFP-N1 from an $\mathrm{N}: \mathrm{P}$ ratio of 2 onwards (Figure 1-Di) as shown by the inability of the pDNA to migrate through the gel. L-NPs followed a similar condensation pattern, where beyond N:P 2 pDNA was retained within gel wells, indicating that NPs remained intact following lyophilisation (Figure 1-Dii).

Lastly, prior to incorporation into the dissolvable PVA matrix, the affect of lyophilisation on pDNA tertiary structure was determined using gel electrophoresis, an established and powerful technique to separate pDNA conformations due to their differing migration rates within an agarose ge ${ }^{27-29}$ (Figure 1-E). To allow migration of pDNA through the agarose gel under current, NPs were incubated with Proteinase K to degrade the RALA peptide prior to 
analysis. Control pDNA can be seen to reside predominantly in the supercoiled, as well as linear and nicked conformations (Figure 1-Ei, Lane 2). Following complexation with RALA (N:P 0-12) and incubation with Proteinase K, pDNA remained in the same conformations as prior to complexation, indicating no damage to pDNA during NP formation (Figure 1-Ei, Lanes 3-10). Following lyophilisation (Figure 1-Eii, Lanes 4-11), there was a loss of the pDNA supercoiled conformation, and increase in the linear and nicked conformations indicating pDNA damage during lyophilisation.

\subsection{NP functionality is not compromised following lyophilisation or incorporation into}

\section{the dissolvable microneedle matrix}

To determine whether NPs retained functionality following lyophilisation, NCTC-929 cells were used as a model cell line for transfection studies (Figure 2-A and -B). Consistent with previously reported data, F- NPs (N:P 6) transfected $61.4 \% \pm 0.4$ of cells. ${ }^{[23]}$ L-NPs with no protectant lost approximately $2 / 3$ transfection efficacy compared to F-NPs $(19.0 \% \pm 3.1)$ indicating damage during the freeze-drying process. Conversely, addition of $5 \% \mathrm{w} / \mathrm{v}$ trehalose prior to lyophilisation was sufficient to conserve $\sim 95 \%$ of NP transfection efficacy $(58.1 \% \pm 4.5)$. To determine the impact of incorporation into the $9-10 \mathrm{kDa}$ PVA matrix, LNPs were directly reconstituted into 9-10 kDa PVA stock solution and dried for $24 \mathrm{~h}$ at RT prior to transfection studies. Following dissolution from the dehydrated polymer gels, NP transfection efficacy decreased to $47.7 \% \pm 14.7$, although this was not significantly lower than the transfection efficacies of F-NPs or L-NPs ( $p>0.05$ ), therefore incorporation into 9$10 \mathrm{kDa}$ PVA was not considered detrimental to the formulation process. 
(A)

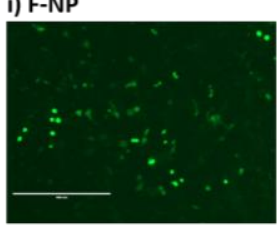

iii) L-NP

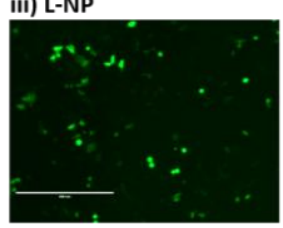

(B)

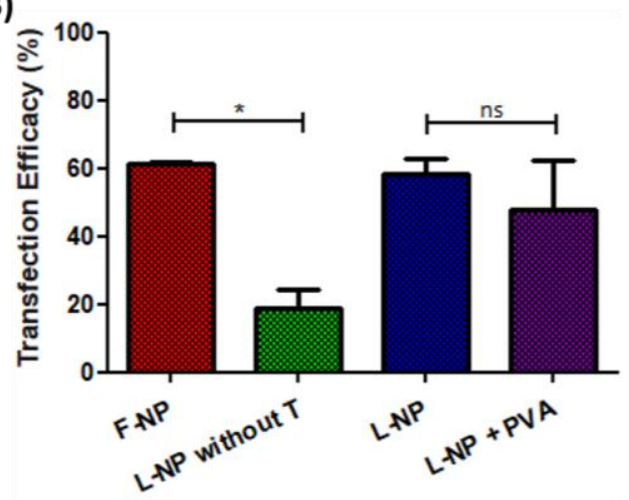

(C)

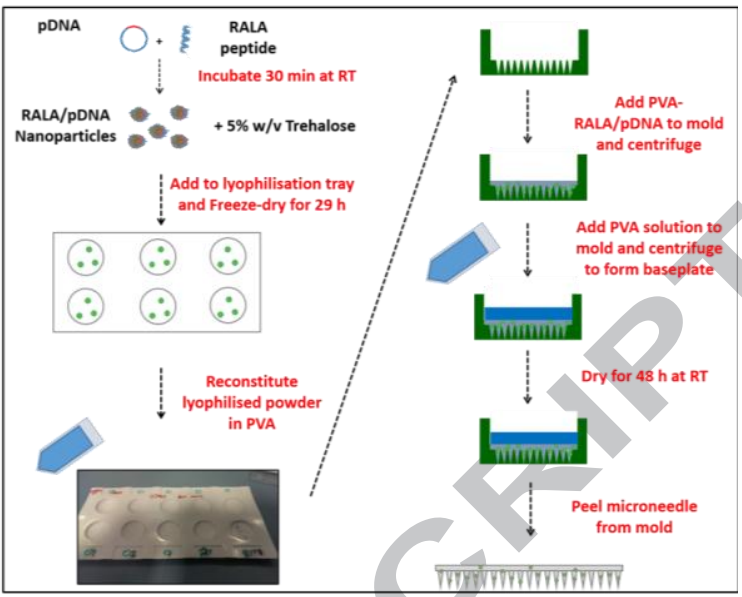

(D)

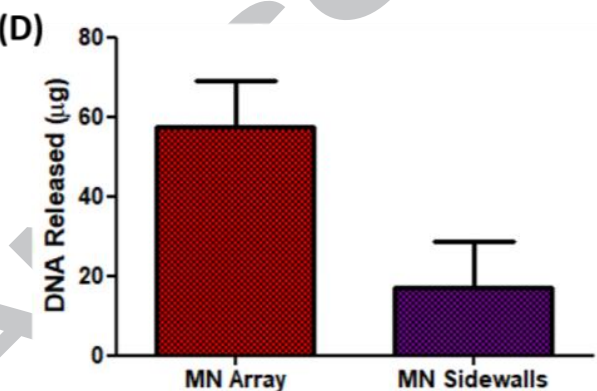

Figure 2. Effect of manufacturing process on NP functionality and release from dissolvable microneedle (MN) array. (A) Typical fluorescent microscope images of GFP transfection within the NCTC-929 cell line following transfection with: i) F-NPs, ii) L-NPs without trehalose (T), iii) L-NPs and iv) L-NPs reconstituted and dried within aqueous PVA (L-NP + PVA); (B) Flow cytometric analysis of GFP expression in the NCTC-929 cell line $48 \mathrm{~h}$ post-transfection with NPs treated as above. Asterisk denotes a significant difference (One-Way ANOVA, $*$ p $<0.05$ ). (C) Schematic representation of dissolvable MN fabrication process; (D) Quantification of pDNA recovery from PVA MNs loaded with L-NPs. Graphs represent mean + SD (N=3 for all studies).

\subsection{Manufacture of and pDNA recovery from dissolvable MN array}

Dissolvable 9-10 kDa PVA arrays were fabricated using $100 \mu \mathrm{g}$ of lyophilised pDNA complexed to RALA (N:P 6) (Figure 2-C) (NP-MN). The quantity of pDNA recovered from the microneedle array (baseplate and microneedles) was determined separately from that in the sidewalls, to allow quantification of the pDNA lost during manufacture, and that available for delivery (Figure 2-D). The quantity of pDNA released from within the array was 57.29 
$\mu \mathrm{g}$. The quantity of pDNA released from the discarded side walls was $17.04 \mu \mathrm{g}$. Hence, the total quantity of pDNA recovered from MNs formulated using the novel manufacturing method was $74.33 \mu \mathrm{g}$, indicating that $25.67 \mu \mathrm{g}$ of pDNA is lost during manufacture. Details of NP transfection efficacy and loading within MN patches following processing and manufacture are suimmarised in Table 1.

Table 1. Transfection Efficacies and loading of NPs within 9-10 kDa PVA microneedle (MN) arrays following various formulation techniques. The transfection efficacy of NPs following a number of processing steps was established in the NCTC-929 cell line. NPs processing was as follows: Fresh NPs (F-NPs); NPs lyophilised with (L-NP) and without Trehalose (L-NP - T); F-NPs incorporated into 9-10 kDa PVA MN matrix (F-NP + PVA); LNP incorporated into 9-10 kDa PVA MN matrix (L-NP + PVA). The loading of NPs within PVA MN patches formulated using the previously reported ${ }^{22}$ (Method 1) and novel (Method 2) manufacturing processes were determined using the Picogreen Assay.

\begin{tabular}{|c|c|c|c|c|}
\hline Treatment & $\begin{array}{l}\text { Transfection Efficacy } \\
\text { in NCTC-929 (\%) }\end{array}$ & $\begin{array}{l}\text { Transfection Efficacy } \\
\text { Relative to F-NPs (\%) }\end{array}$ & $\begin{array}{l}\text { Manufacturing } \\
\text { Method }\end{array}$ & $\begin{array}{l}\text { Microneedle } \\
\text { Loading }(\mu \mathrm{g})\end{array}$ \\
\hline F-NP & 61.4 & 100 & $\mathrm{~N} / \mathrm{A}$ & $\mathrm{N} / \mathrm{A}$ \\
\hline L-NP & 58.1 & 94.6 & N/A & $\mathrm{N} / \mathrm{A}$ \\
\hline L-NP - T & 19.0 & 30.9 & $\mathrm{~N} / \mathrm{A}$ & $N / A$ \\
\hline $\mathrm{F}-\mathrm{NP}+\mathrm{PVA}$ & 36.8 & 59.9 & 1 & 17.7 \\
\hline$L-N P+P V A$ & 47.7 & 77.7 & 2 & 57.3 \\
\hline
\end{tabular}

\subsection{L-NP loaded MN arrays (NP-MN) are functional and mechanically robust}


(A)

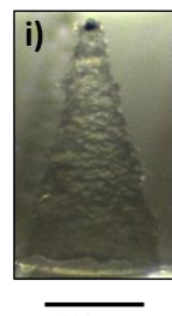

$\overline{200 \mu \mathrm{m}}$
(B)

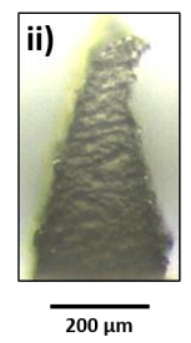

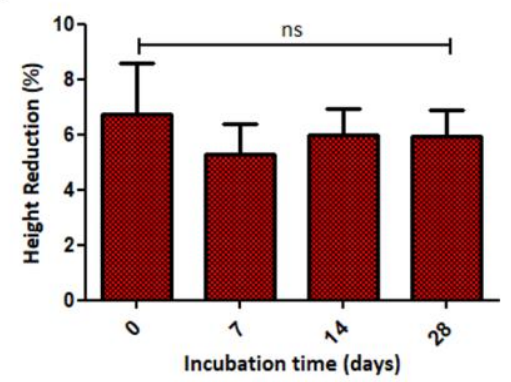

(C)

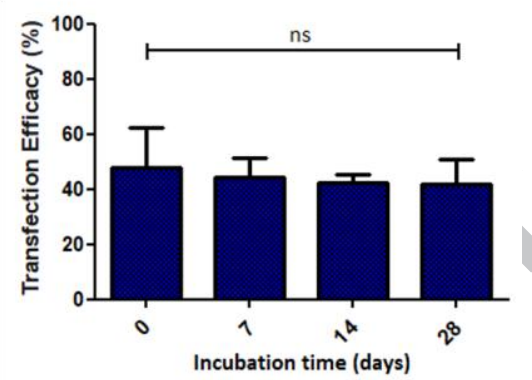

(D)

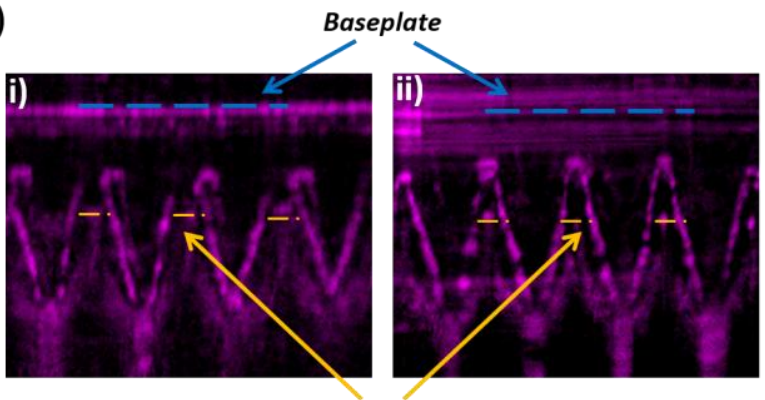

Stratum cornuem
(E)

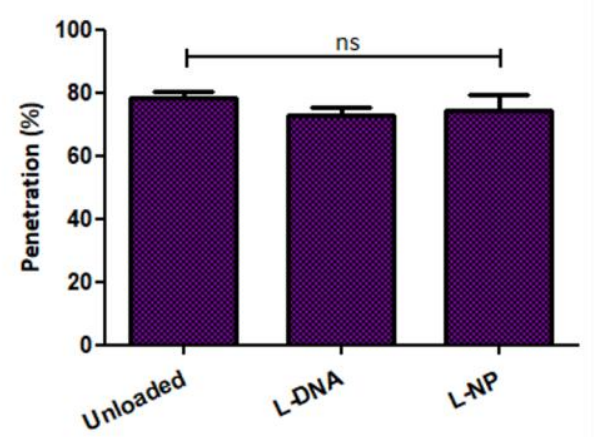

Figure 3. In vitro characterisation of L-NP loaded MNs (NP-MN). (A) Light microscope images of NP-MNs i) prior to and ii) following compression with a $45 \mathrm{~N}$ axial load; (B) Percentage Height Reduction of NP-MNs and (C) Transfection efficacy of L-NP following dissolution from PVA MNs, following incubation at RT over a 28 day period; (D) Optical Coherence Tomography (OCT) Images of i) PVA MNs loaded with lyophilised DNA (DNA-MN) and ii) NP-MNs; (E) Quantification of percentage penetration through the stratum corneum of DNA-MNs and NP-MNs. Graphs represent mean $+\mathrm{SD}(\mathrm{N}=3$ for all studies $)$.

$\mathrm{NP}-\mathrm{MN}$ were dried at RT for $24 \mathrm{~h}$ prior to peeling from the master-mould and imaging prior to (Figure 3-Ai), and following (Figure 3-Aii), compression with an axial force of 45 N. NPMNs formed sharp, conical micro-projections approaching $\sim 600 \mu \mathrm{m}$ in length. Following compression, the tips of arrays showed a blunting, and underwent a height reduction of $6.74 \pm$ $1.8 \%$ although no major mechanical failure/breakage was observed in any of the tested arrays. The short term mechanical and functional stability of NP-MNs was assessed over a 28 day period via axial load compression and flow cytometry. Following 7, 14 and 28 days incubation at RT the percentage height reduction of NP-MNs was 5.26\%, $6.00 \%$ and $5.93 \%$ 
respectively following compression, which was not significantly different than that following 0 days incubation (Figure 3-B, $\mathrm{p}>0.05$ ), indicating that NP-MNs did not lose strength over the 28 day incubation period. Following 7, 14 and 28 days incubation at RT the transfection efficacy of L-NPs (recovered from 9-10 kDa PVA gels) was 44.2\%, 42.3\% and 42.0\% respectively (Figure 3-C). These transfection efficacies were not significantly lower than that achieved by F-NPs $(47.8 \%, \mathrm{p}>0.05)$, indicating that the transfection efficacy was not compromised by short term storage.

To determine whether NP-MNs effectively penetrated the SC, NP-MNs were pressed manually into shaven neonatal porcine skin for $30 \mathrm{~s}$, and imaged using OCT (Figure 3-D). Images revealed that penetration across the SC was deep and consistent with both pDNAloaded (DNA-MNs) (Figure 3-Di) and NP-MNs (Figure 3-Dii). DNA-MNs and NP-MNs achieved penetration depths of $73.0 \%$ and $74.5 \%$ respectively, which was not significantly different than the penetrations achieved with empty 9-10 kDa PVA arrays previously observed (Figure 3-E, p > 0.05) ${ }^{[22]}$

3.5 NP-MNs deliver large quantities of cargo and are capable of eliciting reporter gene expression in vivo 


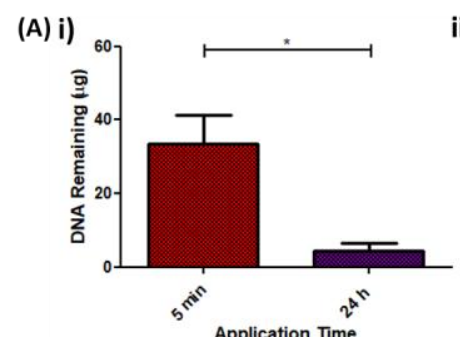

(C) Control

i)

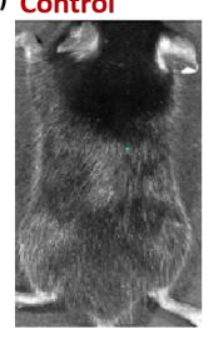

ii)

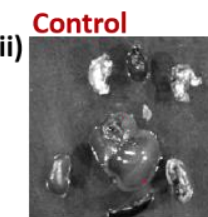

DNA-MN

DNA-MN
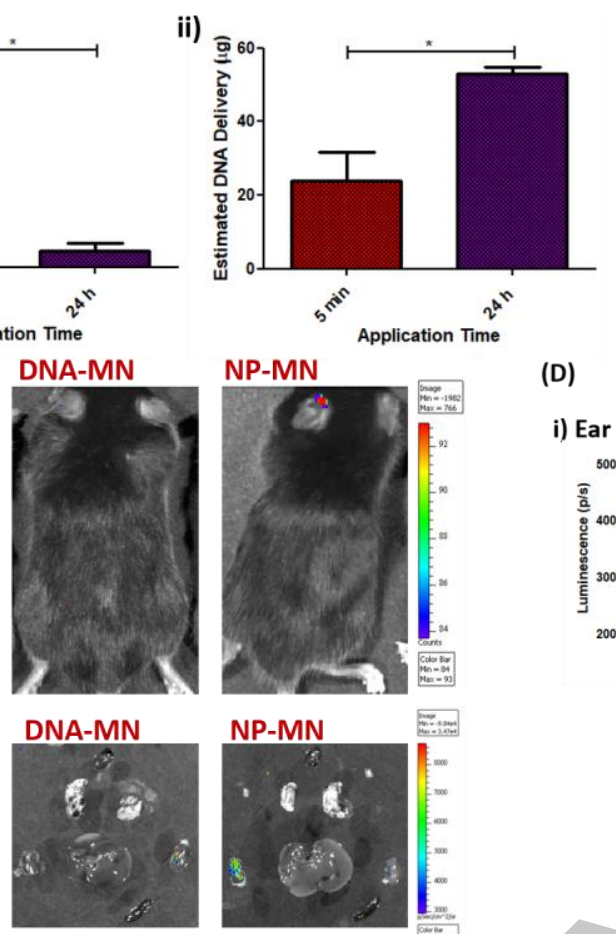

(D)

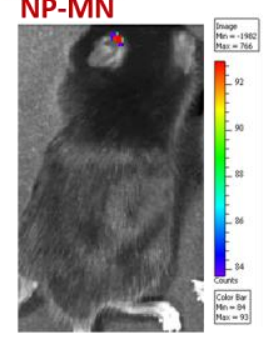

i) Ear
(B)
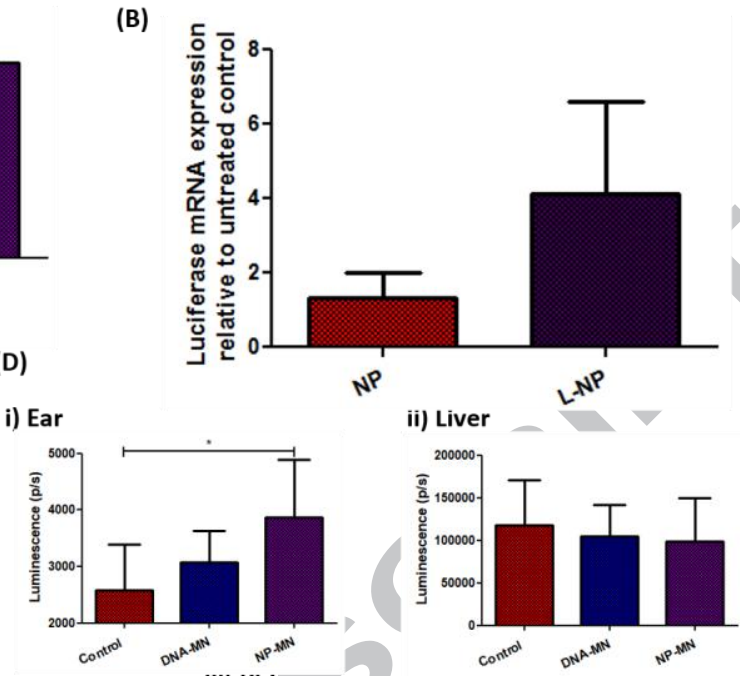

iii) Kidney
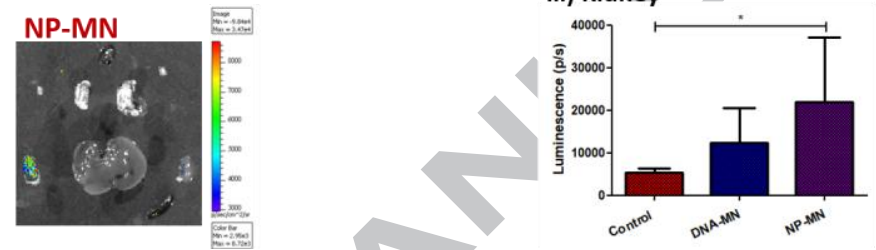

Figure 4: In vivo characterisation of NP-MNs. (A) Quantification of pDNA (i) remaining in and (ii) delivered from NP-MNs following 5 min or $24 \mathrm{~h}$ application to mouse ears. Graphs represent mean + $\mathrm{SD}, \mathrm{N}=3$, asterisk denotes a significant difference (student's t-test, $* \mathrm{p}<0.05$ ). (B) Quantification of luciferase mRNA levels in the ear tissue relative to $\beta$-actin, reported as fold change relative to untreated control. Graph represents mean $+\mathrm{SD}$, (N = 3/4); (C) Representative images of gene expression captured via the IVIS imaging system from the i) dorsal side and ii) harvested organs of mice $48 \mathrm{~h}$ following application of DNA-MN or NP-MN encoding luciferase to the dorsal side of ears; (D) Quantification of gene expression from the i) ears, ii) liver, and iii) kidneys of mice $48 \mathrm{~h}$ following DNA-MN or NP-MN application. Graphs represent mean $+\mathrm{SD}, \mathrm{N}=3$. Asterisk denotes a significant difference (One-Way ANOVA, $* \mathrm{p}<0.05)$.

To estimate the quantity of pDNA which could be delivered from arrays in vivo, NP-MNs were applied to the dorsal side of mouse ears. Following 5 min of application, $33.41 \mu \mathrm{g}$ of pDNA remained in MNs, which was significantly higher than the $4.40 \mu \mathrm{g}$ of pDNA remaining in MNs following $24 \mathrm{~h}$ application time (Figure 4-Ai, $(\mathrm{p}<0.05)$. Hence the 
quantity of pDNA delivered following application of NP-MNs for 5 min or $24 \mathrm{~h}$ was estimated to be $23.88 \mu \mathrm{g}$ and $52.89 \mu \mathrm{g}$ respectively (Figure 4-Aii, $\mathrm{p}<0.05$ ).

The ability of pLUX and RALA/pLUX-loaded MNs to elicit gene expression in vivo was next determined using qRT-PCR and whole body luminescence imaging. Following application of arrays manufactured with $32 \mu \mathrm{g}$ of non-lyophilised pLUX, prepared as previously described, ${ }^{[22]}$ there was no detectable increase in luciferase expression in the ear tissue compared to untreated control (1.343-fold). However, luciferase expression was increased 4.114-fold following application of arrays manufactured with $100 \mu \mathrm{g}$ of L-NPs (Figure 4-B).

Following this, mice were treated with DNA-MNs or NP-MNs and $48 \mathrm{~h}$ following application, luciferase protein expression was analysed using the IVIS imaging system (Figure 4-C). Imaging revealed a significant increase $(\mathrm{p}<0.05)$ in luminescence within ears which had been treated with NP-MNs, compared to control (untreated ears), indicating successful local transfection (Figure 4-Di). Application of DNA-MNs resulted in a small increase in luminescence compared to untreated ears, although this was not significant ( $\mathrm{p}>$ 0.05). To determine whether delivery of cargo into the ear resulted in gene expression beyond the application site, mice were sacrificed and the main organs were imaged. Analysis revealed no significant increase in the luminescence of livers from $\mathrm{MN}$ treated mice compared to control (Figure 4-Dii, $\mathrm{p}>0.05$,). Conversely, kidneys from mice treated with NP-MNs demonstrated significantly increased luminescence compared to untreated mice, (Figure 4-Diii, $\mathrm{p}<0.05$ ), indicating gene expression within the kidney. Although application of DNA-MNs did result in a small increase in luminescence within the kidney, this was not significant $(\mathrm{p}>0.05)$. 


\subsection{RALA/pE6-E7 NPs are functional following lyophilisation and incorporation into the PVA matrix}

Expression of the HPV-16 E6 and E7 proteins following transfection of NCTC-929 cells with F-NPs or L-NPs was confirmed via western blot (Figure 5-A). Expression of each of the proteins was apparent following transfection with NPs, but not with DNA alone, highlighting that RALA is necessary to facilitate transfection. Further to this it was demonstrated that LNPs remained functional following incubation in the polymer matrix over a range of temperatures $\left(4^{\circ} \mathrm{C}, 21^{\circ} \mathrm{C}\right.$ and $\left.37^{\circ} \mathrm{C}\right)$, for up to 28 days (Figure $5-\mathrm{B}$ ).

(A)

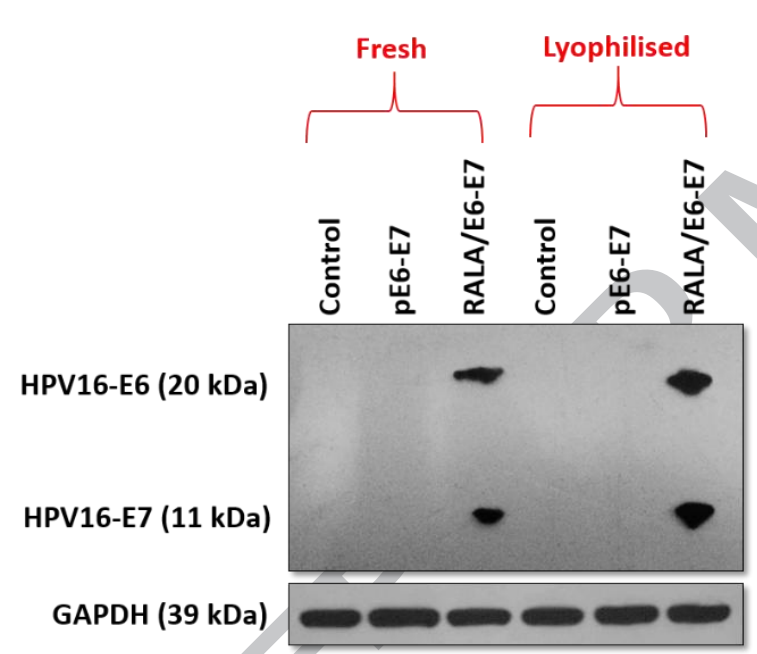

(B)

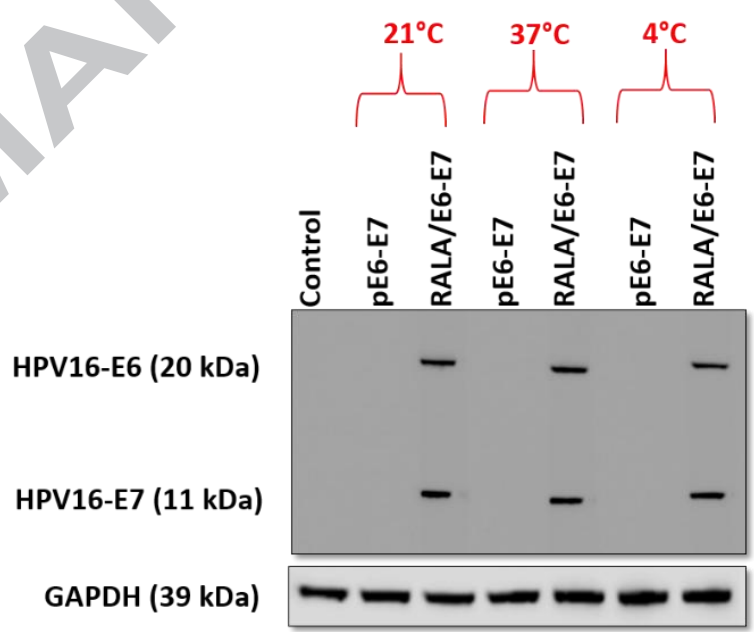

Figure 5: Functionality of pE6-E7 NPs following formulation and storage within NP-MNs. (A) Western Blot analysis of HPV16 E6 and E7 expression $48 \mathrm{~h}$ following transfection of NCTC-929 cells with fresh or lyophilised pE6-E7 DNA and NPs (B) Western Blot analysis of HPV16 E6 and E7 expression $48 \mathrm{~h}$ following transfection of NCTC-929 cells with L-DNA and L-NPs released from the PVA MN matrix following storage at $4^{\circ} \mathrm{C}, 21^{\circ} \mathrm{C}$ or $37^{\circ} \mathrm{C}$ for 28 days. 


\subsection{Immunisation of mice via $\mathrm{MN}$ is able to generate a potent humoural and cellular immune response against the encoded HPV16 E6 and E7 antigens}

Following two or three immunisations, raised serum anti-E6/E7 IgG levels were present in all experimental groups compared to control mice, with the exception of mice treated with empty MNs (Figure 6-A). Mice immunised with NP-MN showed the highest levels of antigenspecific IgG $(80.06 \mu \mathrm{g} / \mathrm{mL}$ and $61.64 \mu \mathrm{g} / \mathrm{mL}$ after 2 or 3 immunisations respectively), which were significantly higher than those of naïve mice at the same time points $(24.68 \mu \mathrm{g} / \mathrm{mL}$ and $25.56 \mu \mathrm{g} / \mathrm{mL}, \mathrm{p}<0.05)$.

The cytolytic activity of splenic $\mathrm{T}$ cells, from immunised and untreated mice, against TC-1 tumour cells was assessed using the LDH release assay (Figure 6-B). The highest level of TC-1 cell lysis was observed in mice immunised with NP-MN, which was double that observed in untreated controls (43.3\% vs $21.4 \%, \mathrm{p}>0.05)$. An increased TC- 1 specific cell lysis was also observed in mice immunised with NP-IM (37.38\%), DNA-IM (33.58\%) or DNA-MN (30.89\%).

Lastly, the ability of RALA encapsulated pE6-E7 to evoke a specific cytolytic T cell response was tested in established TC-1 tumours (Figure 6-D). Mice treated with NP-IM showed a considerable decrease in final tumour mass compared to untreated control mice $(0.997 \mathrm{~g}$ and 2.29 g respectively, $\mathrm{p}>0.05)$. However, this decrease was markedly enhanced by treating with NP-MN (0.629 g, p < 0.05,). Conversely, treatment with DNA-IM or DNA-MN did not result in a decrease in tumour mass (1.695 $\mathrm{g}$ and $2.170 \mathrm{~g}$ respectively) indicating that complexation with the RALA peptide was necessary to induce a therapeutic response in vivo. 
(A)

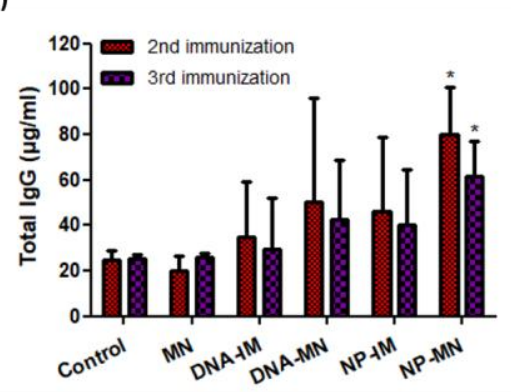

(B)

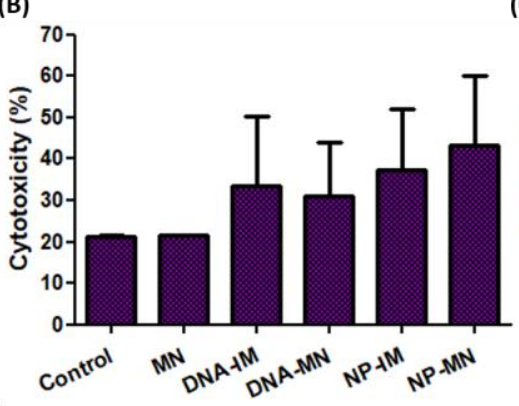

(C)

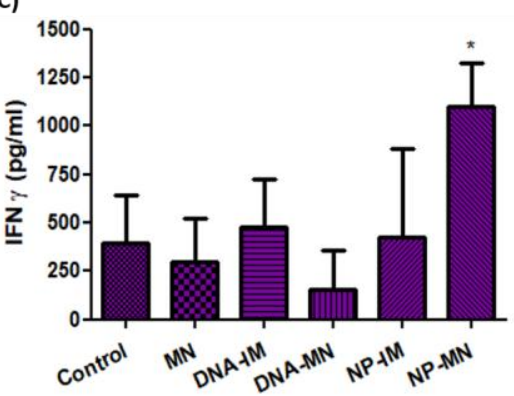

(D)

i)

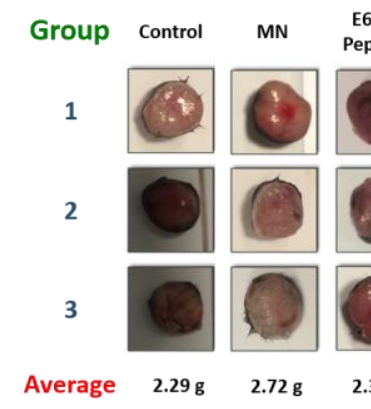

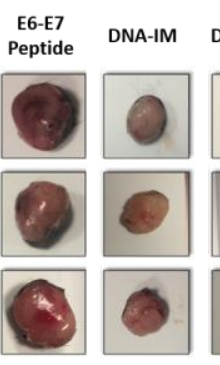

$2.33 \mathrm{~g} \quad 1.70 \mathrm{~g}$

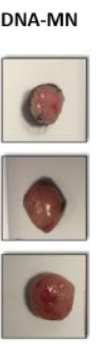

$2.17 \mathrm{~g}$

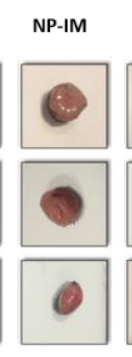

$1.00 \mathrm{~g}$ ii)

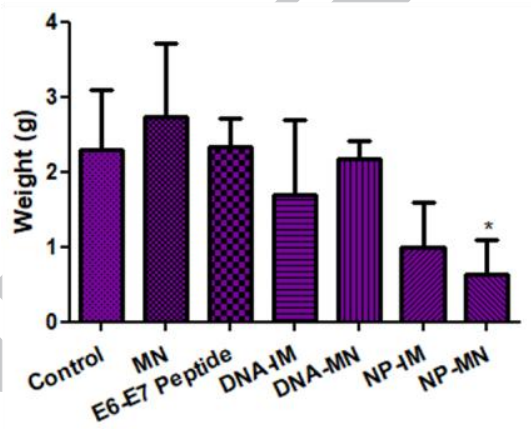

Figure 6: Evaluation of NP-MN mediated immune response to E6-E $7^{+}$TC-1 cervical cancer cells in vivo. Mice were treated with empty MN (MN), DNA-IM, DNA-MN, NP-IM and NP-MN three times at two weekly intervals. Following sacrifice splenic $\mathrm{T}$ cells were harvested, purified and stimulated in vitro with irradiated TC- 1 cells. (A) Evaluation of serum antigen-specific IgG titres one week following the second and third immunisations. Graph represents mean $+\mathrm{SD},(\mathrm{N}=3 / 4)$. Asterisk denotes a significant difference (One-Way ANOVA, * $\mathrm{p}<0.05$ ).; (B) Determination of $\mathrm{T}$ cellmediated toxicity of healthy TC- 1 cells, following 6 days co-culture with irradiated TC-1 cells; (C) Determination of IFN- $\gamma$ secretion from isolated $\mathrm{T}$ cells following 4 days co-culture with irradiated TC- 1 cells. Graphs B and C represent mean $+\mathrm{SD},(\mathrm{N}=3 / 4)$. Asterisk denotes a significant difference (One-Way ANOVA, * p < 0.05). (D) Mice were challenged with 1 x $10^{5}$ TC- 1 cells i.d. on the rear dorsum. When tumours reached $50 \mathrm{~mm}^{3}$ mice received three immunisations as above at weekly intervals. One week following the final immunisation tumours were harvested and weighed. Graph represents mean $+\mathrm{SD}, \mathrm{N}=3$. Asterisk denotes a significant difference (One-Way ANOVA, * $\mathrm{p}<$ $0.05)$. 


\section{Discussion}

Previously we reported on the fabrication of a novel two-tiered delivery system comprised of a dissolvable polymer MN matrix, encapsulating cationic RALA/pDNA NPs. ${ }^{[13,22]}$ During the manufacturing process the loading capacity of the device was limited by the volume of solution which could be diluted into the dissolvable matrix without compromising the physical integrity of the dried formulation. ${ }^{[22]}$ This is a common limitation of coated and dissolvable $\mathrm{MN}$ formulations where the payload is frequently $<10 \mu \mathrm{g} .^{[18,19,30]}$ Attempts to increase the concentration of pDNA solutions prior to incorporation into the MN matrix are constrained by the inherent viscosity of pDNA, and the instability of over-concentrated cationic NPs in solution. ${ }^{[19,31,32]}$ Increasing this restricted payload would be a significant advancement for MN-based DNA vaccines for two reasons: Firstly, delivery of a higher quantity of pDNA is likely to result in higher levels of antigen expression. Secondly, pDNA vaccines possess inherent adjuvant activity due to the presence of $\mathrm{CpG}$ motifs in the plasmid backbone, which promote DC activation through toll-like receptor 9 (TLR9) stimulation, as such, delivery of greater quantities of pDNA will result in greater DC maturation, migration and $\mathrm{T}$ cell priming. This prompted us to develop a novel manufacturing process using lyophilisation to increase MN loading capacity. By removing water from the cargo solution and directly reconstituting the lyophilised cake into a smaller volume of aqueous MN matrix we hypothesised we could significantly increase the device payload compared to our previously described formulations. ${ }^{[22]}$ This process has been explored previously to concentrate inactivated influenza vaccine $(\mathrm{A} / \mathrm{PR} / 8 / 34),{ }^{[33]}$ and Human Papilloma Virus Pseudoviruses (HPV-PsV), within dissolvable and coated MNs, ${ }^{[34]}$ however, no studies have utilised lyophilisation to concentrate pDNA or pDNA-based cationic NPs within dissolvable MNs. 
However, lyophilisation can be detrimental to NP size, zeta potential and encapsulation efficiency, due to the stresses placed on particles during freezing and drying. ${ }^{[32,35-37]}$ Trehalose has demonstrated the ability to conserve the functionality of NPs during lyophilisation without the need for other excipients, ${ }^{[38,39]}$ and therefore was selected for initial studies examining the physical integrity of the L-NPs. The addition of $5 \% \mathrm{w} / \mathrm{v}$ trehalose during lyophilisation was unable to fully conserve NP size, however complex sizes were maintained $<150 \mathrm{~nm}$, which is essential for efficient endocytosis.$^{[40]}$. L-NPs also maintained a cationic zeta potential and encapsulated pDNA in a manner similar to F-NPs, indicating that the electrostatic interactions between the cationic RALA peptide and anionic pDNA are sufficiently strong to prevent any pDNA dissociation during lyophilisation.

Examination of pDNA integrity within L-NPs revealed a notable loss of the supercoiled conformation, especially where pDNA was complexed to a lower concentration of RALA. This is due to the decreased zeta potential at low N:P ratios, which leads to greater aggregation, and pDNA damage, due to reduced charge repulsion. ${ }^{[23]}$ Interestingly, Mohajel et al (2012) noted that despite lyophilisation of chitosan/pDNA complexes resulting in a loss of the supercoiled portion of pDNA, which is considered the most important conformation for achieving high transfection efficacies, ${ }^{[41]}$ this did not affect the transfection efficacy of the polyplexes. ${ }^{[42]}$ Similarly, we found that L-NPs retained $\sim 95 \%$ transfection efficacy. Assessment of cell viability following transfection with F-NPs and L-NPs confirmed that complexes were not toxic, and it was concluded that the L-NPs were suitable for incorporation into dissolvable MNs.

Previous studies have indicated the need to determine the cargo functionality following both lyophilisation and incorporation into the $\mathrm{MN}$ formulation, due to the stresses of a secondary drying step within the polymer matrix, which may result in aggregation. ${ }^{[33]}$ Indeed, L-NPs demonstrated an approximate $25 \%$ decrease in transfection efficacy following incorporation 
into PVA (61.4\% vs $47.7 \%)$, and therefore in future studies, optimising the drying process or including additional protectants within the aqueous MN matrix may be beneficial to conserve activity during $\mathrm{MN}$ formulation. ${ }^{[20,43,44]}$ However, we did not investigate these strategies in the present study, as NPs retained a high transfection rate ( $75 \%$ compared to F-NPs).

We next demonstrated that this novel fabrication process could be used to increase the pDNA MN loading compared to our previously reported cumbersome fabrication process. ${ }^{[22]}$ Formulated MNs resembled those manufactured previously, with sharp uniform tips, and heights approximate to the shape of the mastermould. NP-MNs resisted major deformation or fracture under compression forces necessary for manual application, ${ }^{[45]}$ and penetrated neonatal porcine skin in a similar manner to unloaded arrays. This novel fabrication process allowed an approximate seven fold concentration of the NP cargo, and permitted a loading of $57 \mu \mathrm{g}$ of pDNA per MN (in addition to $496 \mu \mathrm{g}$ of RALA peptide), which is significantly higher than the loadings achieved by other authors. For example, Gonzalez-Gonzalez et al (2010) succeeded in loading their PVA-based micron-scale Protrusion Array Device (PAD) with 144 ng of pDNA, ${ }^{18}$ while Liao et al (2017) achieved greater loadings of $\sim 20 \mu \mathrm{g}$ of pDNA per device in PVA/PVP microneedles. ${ }^{29}$

In vivo application of MNs allowed deposition of $\sim 50 \mu \mathrm{g}$ of pDNA per patch, which is a significant improvement over the quantities of pDNA which have previously been delivered from similar dissolvable MNs. ${ }^{[13,18]}$ qRT-PCR confirmed that increasing the payload resulted in higher levels of local luciferase mRNA expression compared to our previously described MN patch which was able to deliver $\sim 12 \mu \mathrm{g}$ of pDNA. ${ }^{[22,24]}$ Further to this it was established that arrays were capable of eliciting protein expression in vivo, as this is a prerequisite to the induction of an immune response. Our previously described MN system was only able to produce detectable levels of gene expression within the highly vascularised liver and kidneys, indicating systemic uptake, and accumulation within these organs. ${ }^{[13,23]}$ While the expression 
of immunogenic protein(s) within organs other than the skin is not expected to result in any off-target toxicity, the epidermis and dermis are the primary targets for vaccination owing to their wealth of APCs. Therefore this novel formulation is more ideal for DNA vaccination purposes, as treatment generated local gene expression within the ear, as well as the kidneys, of mice.

One of the reported major advantages of dissolvable MNs has been the supposition that cargo stored within the dry state may be more stable than liquid vaccines which require refrigeration. Two parameters which commonly affect the usability of dissolvable MNs over storage include a loss of strength or shape due to imbibing environmental water, ${ }^{[46]}$ and secondly, loss of cargo functionality. ${ }^{[43,44]}$ However, over a 28 day period no significant change in MN strength or cargo functionality were noted, indicating that MNs should retain sufficient strength to penetrate the SC and may protect cargo without the need for cold chain storage.

Finally, we tested the efficacy of this novel NP-MN system in a preclinical cervical cancer model. NP-MN evoked the greatest antigen-specific humoural response in immunized mice, with the E6 and E7 specific IgG titers being approximately 1.7 fold higher than those elicited by NP-IM. This supports that delivery to the APC-rich layers of the dermis and epidermis enhance DNA vaccine immunogenicity. Furthermore, antibody titres induced by NP-MN were 1.6 fold higher than those elicited DNA-MN, demonstrating that RALA significantly improves cellular uptake, and hence activation of an immune response. To be effective against established infections or tumours, DNA vaccines must also be capable of generating antigen-specific CTLs which are capable of directly lysing infected or cancerous cells. ${ }^{8}$ Immunisation of mice with NP-MN resulted in the largest increase in TC-1 specific cytotoxicity via isolated CD8+ T cells, which was two-fold higher than that of unimmunised mice. Furthermore, antigen-specific IFN- $\gamma$ secretion was significantly raised only from $\mathrm{T}$ 
cells isolated from animals immunised with NP-MN, highlighting the superiority of this DNA vaccination system. Most importantly, we demonstrated the ability of NP-MNs to retard the growth of established TC -1 tumours in vivo. NP-MN treatment proved the most effective in reducing tumour burden and significantly reduced (3.6 fold) tumour weight compared to control mice, demonstrating that this system is able to generate a potent therapeutic antitumour effect. In agreement with others we found that naked pDNA was poorly immunogenic, and that i.d. immunisation significantly increased vaccine potency. ${ }^{[11,15,19]}$

In conclusion, by utilising lyophilisation to concentrate pDNA cargo we have successfully overcome one of the main limitations of coated and dissolvable $\mathrm{MN}$ formulations, ie the limited loading capacity compared to other systems. This dissolvable MN prototype is an ideal DNA vaccine delivery system encompassing a high payload within the device itself, allowing decreased storage requirements and greater functionality.

\section{Acknowledgements}

This research was supported by an Invest Northern Ireland Proof of Concept Grant (PoC330) and a Prostate Cancer UK Award (S12-006). 


\section{References}

[1. Cole, G., McCaffrey, J., Ali, A. A. \& McCarthy, H. O. DNA vaccination for prostate cancer: key concepts and considerations. Cancer Nanotechnol. 6, 2 (2015).

2. Bonnet, J. et al. Chain and conformation stability of solid-state DNA: implications for room temperature storage. Nucleic Acids Res. 38, 1531-46 (2010).

3. Suhrbier, A. Multi-epitope DNA vaccines. Immunol. Cell Biol. 75, 402-8 (1997).

4. Gummow, J. et al. A Multiantigenic DNA Vaccine That Induces Broad Hepatitis C Virus-Specific T-Cell Responses in Mice. J. Virol. 89, 7991-8002 (2015).

5. Hisazumi, J., Kobayashi, N., Nishikawa, M. \& Takakura, Y. Significant role of liver sinusoidal endothelial cells in hepatic uptake and degradation of naked plasmid DNA after intravenous injection. Pharm. Res, 21, 1223-8 (2004).

6. Lechardeur, D. \& Lukacs, G. L. Intracellular barriers to non-viral gene transfer. Curr. Gene Ther. 2, 183-94 (2002).

7. McCaffrey, J., Donnelly, R. F. \& McCarthy, H. O. Microneedles: an innovative platform for gene delivery. Drug Deliv. Transl. Res. 5, 424-37 (2015).

8. Zhang, N. \& Bevan, M. J. CD8(+) T cells: foot soldiers of the immune system. Immunity 35, 161-8 (2011).

9. Venus, M., Waterman, J. \& McNab, I. Basic physiology of the skin. Surg. 29, 471-474 (2011).

10. Mann, E. R. Review: Skin and the Immune System. J. Clin. Exp. Dermatol. Res. 4, (2014).

11. Chen, X. et al. Improved DNA vaccination by skin-targeted delivery using dry-coated 
densely-packed microprojection arrays. J. Control. Release 148, 327-33 (2010).

12. Donnelly, R. F. et al. Hydrogel-Forming Microneedle Arrays Can Be Effectively Inserted in Skin by Self-Application: A Pilot Study Centred on Pharmacist Intervention and a Patient Information Leaflet.

13. McCaffrey, J. et al. Transcending epithelial and intracellular biological barriers; a prototype DNA delivery device. J. Control. Release 226, 238-247 (2016).

14. Gill, H. S., Denson, D. D., Burris, B. A. \& Prausnitz, M. R. Effect of microneedle design on pain in human volunteers. Clin. J. Pain 24, 585-94 (2008).

15. Mikszta, J. A. et al. Improved genetic immunization via micromechanical disruption of skin-barrier function and targeted epidermal delivery. Nat. Med. 8, 415-9 (2002).

16. Gill, H. S., Söderholm, J., Prausnitz, M. R. \& Sällberg, M. Cutaneous vaccination using microneedles coated with hepatitis C DNA vaccine. Gene Ther. 17, 811-814 (2010).

17. Daugimont, L. et al. Hollow microneedle arrays for intradermal drug delivery and DNA electroporation. J. Membr. Biol. 236, 117-25 (2010).

18. Gonzalez-Gonzalez, E. et al. Silencing of reporter gene expression in skin using siRNAs and expression of plasmid DNA delivered by a soluble protrusion array device (PAD). Mol. Ther. 18, 1667-74 (2010).

19. Kim, Y.-C. et al. Increased immunogenicity of avian influenza DNA vaccine delivered to the skin using a microneedle patch. Eur. J. Pharm. Biopharm. 81, 239-47 (2012).

20. Pearton, M. et al. Microneedle delivery of plasmid DNA to living human skin: Formulation coating, skin insertion and gene expression. J. Control. Release 160, 5619 (2012). 
21. McGrath, M. G. et al. Production of dissolvable microneedles using an atomised spray process: effect of microneedle composition on skin penetration. Eur. J. Pharm. Biopharm. 86, 200-11 (2014).

22. Cole, G. et al. Dissolving microneedles for DNA vaccination : Improving functionality via polymer characterization and RALA complexation. Hum. Vaccin. Immunother. 13, $50-62$ (2017).

23. McCarthy, H. O. et al. Development and characterization of self-assembling nanoparticles using a bio-inspired amphipathic peptide for gene delivery. J. Control. Release 189, 141-9 (2014).

24. Ali, A. A. et al. DNA vaccination for cervical cancer; a novel technology platform of RALA mediated gene delivery via polymeric microneedles. Nanomedicine Nanotechnology, Biol. Med. 13, 921-932 (2017).

25. Donnelly, R. F. et al. Design, optimization and characterisation of polymeric microneedle arrays prepared by a novel laser-based micromoulding technique. Pharm. Res. 28, 41-57 (2011).

26. Anchordoquy, T. J., Armstrong, T. K. \& Molina, M. d. C. Low Molecular Weight Dextrans Stabilize Nonviral Vectors During Lyophilization at Low Osmolalities: Concentrating Suspensions by Rehydration to Reduced Volumes. J. Pharm. Sci. 94, 1226-1236 (2005).

27. Roberts, G. A. \& Dryden, D. T. in DNA Electrophoresis Methods and Protocols Methods in Molecular Biology vol. 1054 (ed. Makovets, S.) 1-10 (Springer, 2013).

28. Yang, H.-W. et al. Ebola Vaccination Using a DNA Vaccine Coated on PLGAPLL/ $\gamma$ PGA Nanoparticles Administered Using a Microneedle Patch. Adv. Healthc. 
Mater. 6, 1600750 (2017).

29. Liao, J. et al. Self-Assembly DNA Polyplex Vaccine inside Dissolving Microneedles for High-Potency Intradermal Vaccination. Theranostics 7, 2593-2605 (2017).

30. Gill, H. S. \& Prausnitz, M. R. Coated microneedles for transdermal delivery. J. Control. Release 117, 227-37 (2007).

31. Kim, Y.-C., Yoo, D.-G., Compans, R. W., Kang, S.-M. \& Prausnitz, M. R. Crossprotection by co-immunization with influenza hemagglutinin DNA and inactivated virus vaccine using coated microneedles. J. Control. Release 172, 579-88 (2013).

32. Abdelwahed, W., Degobert, G., Stainmesse, S. \& Fessi, H. Freeze-drying of nanoparticles: Formulation, process and storage considerations. Adv. Drug Deliv. Rev. 58, 1688-1713 (2006).

33. Sullivan, S. P. et al. Dissolving polymer microneedle patches for influenza vaccination. Nat. Med. 16, 915-20 (2010).

34. Kines, R. C. et al. Vaccination with human papillomavirus pseudovirus-encapsidated plasmids targeted to skin using microneedles. PLoS One 10, e0120797 (2015).

35. Anchordoquy, T. J., Carpenter, J. F. \& Kroll, D. J. Maintenance of Transfection Rates and Physical Characterization of Lipid/DNA Complexes after Freeze-Drying and Rehydration. Arch. Biochem. Biophys. 348, 199-206 (1997).

36. Molina, M. D. C., Dean Allison, S. \& Anchordoquy, T. J. Maintenance of nonviral vector particle size during the freezing step of the lyophilization process is insufficient for preservation of activity: Insight from other structural indicators. J. Pharm. Sci. 90, 1445-1455 (2001).

37. Anchordoquy, T. J., Armstrong, T. K. \& Molina, M. C. Low Molecular Weight 
Dextrans Stabilize Nonviral Vectors During Lyophilization at Low Osmolalities :

Concentrating Suspensions by Rehydration to Reduced Volumes. 94, 7-9 (2005).

38. Cordone, L. et al. Role of residual water hydrogen bonding in sugar/water/biomolecule systems: a possible explanation for trehalose peculiarity. J. Phys. Condens. Matter 19, 205110 (2007).

39. L M Crowe, D. S. R. J. H. C. Is trehalose special for preserving dry biomaterials? Biophys. J. 71, 2087 (1996).

40. Bishop. An Update on Non-clathrin-coated Endocytosis. Rev. Med. Virol. 7, 199-209 (1997).

41. Ramgopal, Y., Mondal, D., Venkatraman, S. S. \& Godbey, W. T. Sustained release of complexed and naked DNA from polymer films. J. Biomed. Mater. Res. B. Appl.

Biomater. 85, 496-503 (2008).

42. Mohajel, N. et al. Drying of a plasmid containing formulation: chitosan as a protecting agent. Daru J. Pharm. Sci. 20, 22 (2012).

43. Kim, Y.-C., Quan, F.-S., Compans, R. W., Kang, S.-M. \& Prausnitz, M. R. Stability kinetics of influenza vaccine coated onto microneedles during drying and storage.

Pharm. Res. 28, 135-44 (2011).

44. Chu, L. Y. et al. Enhanced Stability of Inactivated Influenza Vaccine Encapsulated in Dissolving Microneedle Patches. Pharm. Res. 33, 868-78 (2016).

45. Larrañeta, E. et al. A proposed model membrane and test method for microneedle insertion studies. Int. J. Pharm. 472, 65-73 (2014).

46. Zhu, Z. et al. Rapidly Dissolvable Microneedle Patches for Transdermal Delivery of Exenatide. Pharm. Res. 31, 3348-3360 (2014). 
Graphical abstract
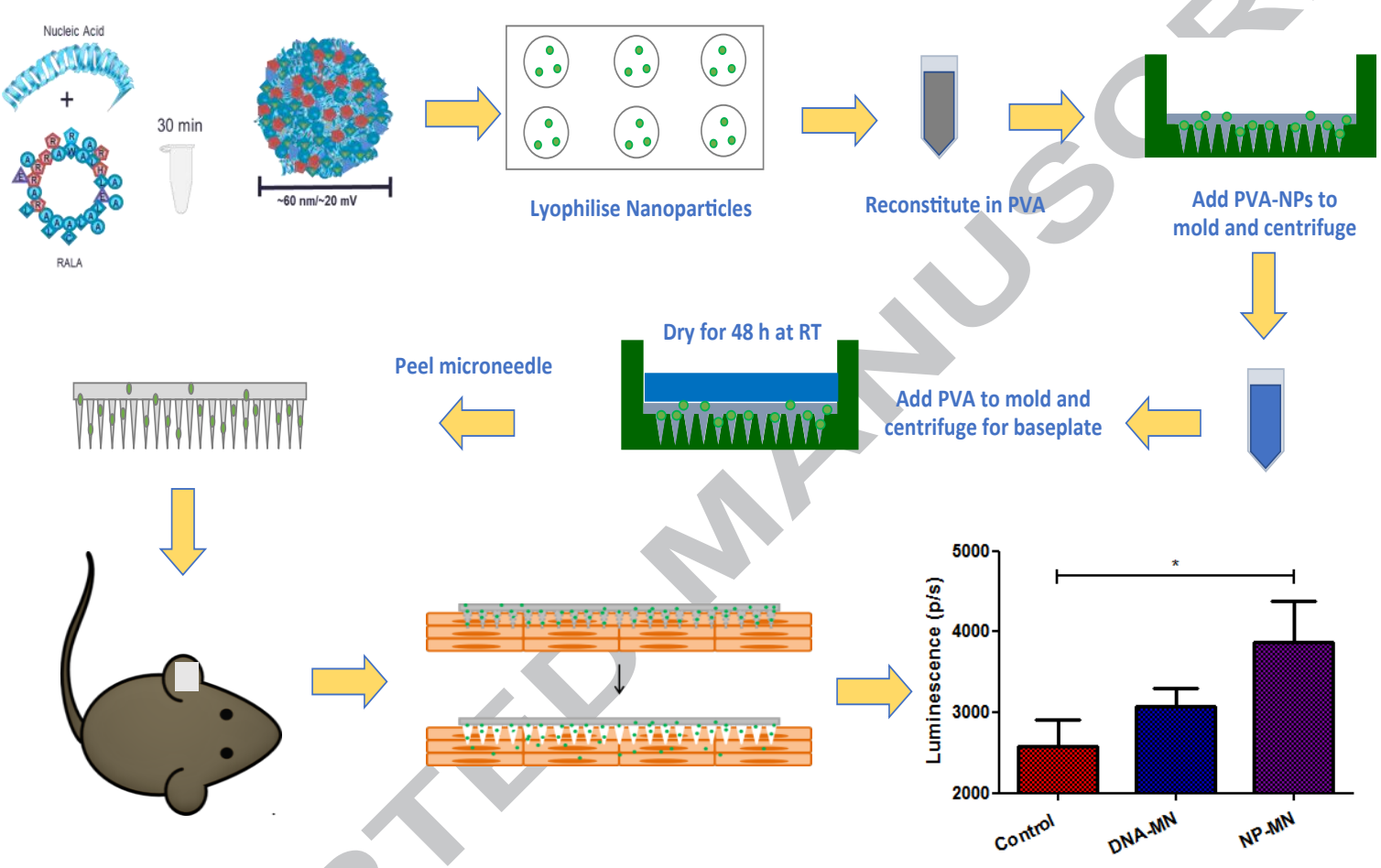


\begin{tabular}{|c|c|c|c|c|}
\hline Treatment & $\begin{array}{l}\text { Transfection Efficacy in NCTC-929 } \\
\text { (\%) }\end{array}$ & $\begin{array}{l}\text { Transfection Efficacy Relative to F-NPs } \\
\text { (\%) }\end{array}$ & Manufacturing Method & Microneedle Loading $(\mu \mathrm{g})$ \\
\hline F-NP & 61.4 & 100 & $\mathrm{~N} / \mathrm{A}$ & $\mathrm{N} / \mathrm{A}$ \\
\hline L-NP & 58.1 & 94.6 & $\mathrm{~N} / \mathrm{A}$ & $\mathrm{N} / \mathrm{A}$ \\
\hline L-NP - T & 19.0 & 30.9 & $\mathrm{~N} / \mathrm{A}$ & $\mathrm{N} / \mathrm{A}$ \\
\hline $\mathrm{F}-\mathrm{NP}+\mathrm{PVA}$ & 36.8 & 59.9 & 1 & 17.7 \\
\hline$L-N P+P V A$ & 47.7 & 77.7 & 2 & 57.3 \\
\hline
\end{tabular}

